\title{
Regional Variation in Food Security in Nepal
}

\author{
Prem Bhandari
}

\begin{abstract}
Food security is a global challenge. This paper examines the regional variation in household food security in Nepal. Specifically, I examine the variation in household level food security with particular reference to newly formed provinces constructed as per the new constitution (2015) of the country, three ecological regions and rural-urban locations of households. I use the nationally representative data from 2011 Nepal Demographic Health Survey to investigate the issue. Using both descriptive as well as multivariate analysis, evidences show that there is regional variation in overall food security in Nepal. Findings show that food security is a problem of rural households. Moreover, food security status of households also significantly varied by province. Households living in Karnali and Far-west provinces (province 6 and 7) located in the western part of Nepal are more food insecure as compared to those living in other provinces. Food security status of households also varied by domains of food security. While anxiety about food supply was an issue for households in the mountains and the hills, food security in terms of quality was equally important in all three ecological regions. However, interestingly, quantity of intake was not a major issue in all the three ecological regions. All three domains were important for households that live in rural areas as well as those living in provinces other than those in Karnali and Far-west provinces. These findings provide a macro level snap shot of food security situation of Nepal and are deemed important for the newly formed federal and provincial governments for food policy framing. Further investigation at the micro-level is necessary for more concrete policies.
\end{abstract}

Keywords: access, food security, region, Nepal, South Asia

\section{Introduction}

This paper examines the regional variation in household food security in Nepal. Specifically, I examine variation in household level food security with particular reference to newly formed provinces constructed as per the new constitution of the country, three ecological regions and rural-urban locations of households. I use the nationally representative data from 2011 Nepal Demographic Health Survey (NDHS) to investigate the issue.

Although food security is a global challenge, it is one of the major issues in developing countries. The United Nation's World Food Programme (WFP) reported that 110 out of 210 countries - primarily poor countries with subsistence agriculture - are facing food security problems and this number is expected to grow (FAO et al., 2013). In 2013, still 767 million people lived below the extreme poverty line globally (United Nations, 2017). According to the United Nations, about 793 million people were undernourished in 2014-2016, which decreased from 930 million in 2000-2002. United Nations (2017) further reported that in 2014-2016, Southern Asia and sub-Saharan Africa alone accounted for 63 per cent of the undernourished people. In 2012-2014, South Asia alone hosted 276 million (16 percent) undernourished people, which was declined from 292 million (24 percent) from 1990-92 (FAO, 2014).

Nepal is one of the most food insecure countries in the world and ranks 157 among 187 countries (UNDP, 2011; Joshi et al., 2012). Based on international benchmark for extreme poverty of an income of US\$ 1.25 per day, about one quarter of the Nepali population is still below poverty line. The proportion decreased from 42 percent in 1995 to 24 percent in 2015 (Government of Nepal, 2015). In 2010/2011, of the Nepal's 75 districts, 38 are characterized as food insecure districts (Government of Nepal, 2012). Among them, 2 districts were self-sufficient for less than three months, 3 districts were food secure for 3-6 months, 14 were secure for 6-9 months and 19 districts were secure for 9-12 months. Nepal requires much attention to overcome food security problem to meet the Sustainable Development Goals.

The Government of Nepal (GoN) aims to eradicate extreme poverty and end hunger and all forms of malnutrition by ensuring access to safe, nutritious and sufficient food all year round for all people by 2030 through its sustainable development goals programs (GoN, 2015). However, there are inequalities in the rates of poverty and state of food security across social groups and regions. Understanding the dire need, this paper attempts to investigate the extent to which household food security varies by regions (administrative, ecological and ruralurban regions), specifically by focusing on seven newly formed federal provinces in the country. The findings from this research will be an important guide to the newly formed provincial governments in designing and pursuing provincial level food security policies. 


\section{The Concept of Food Security}

Food security is a complex concept and is multidimensional in nature. Defining as well as measuring the concept per se is not an easy task. According to Maxwell (1996), in 1996, there are over two hundred definitions of food security. There is no doubt that this number has multiplied over time.

In 1974, for the first time, the World Food Conference (1974) defined food security in terms of food supply as the "Availability at all times of adequate world food supplies of basic foodstuffs to sustain a steady expansion of food consumption and to offset fluctuations in production and prices". In 1983, Food and Agriculture Organization (FAO) broadened the definition that focused on food access. According to FAO, food security is defined as: "Ensuring that all people at all times have both physical and economic access to the basic food that they need" (FAO, 1983). USAID (1992) also defined this concept as a state in which "all people at all times have both physical and economic access to sufficient food to meet their dietary needs for a productive and healthy life". In 1996, the World Food Summit (1996) defined this concept as: "Food security exists when all people, at all times, have physical and economic access to sufficient, safe and nutritious food that meets their dietary needs and food preferences for an active and healthy life". This definition has acquired the broadest acceptance.

As opposed, food insecurity is the limited or uncertain availability of nutritionally adequate and safe foods or limited or uncertain ability to acquire acceptable foods in socially acceptable ways. According to FAO, food insecurity is "a situation that exists when people lack secure access to sufficient amounts of safe and nutritious food for normal growth and development and an active and healthy life" (Napoli 2010/11; Smith et al., 1993).

There are four dimensions of food security: availability, access, utilization, and stability (Napoli, 2010/11; FAO, 2006). According to Napoli, food availability, accessibility, and utilization are among the physical dimensions and stability is the temporal dimension. The nutritional status (the ultimate outcome) is determined by its utilization, which depends upon availability and accessibility of food.

\section{Measuring Food Security}

There are several ways of measuring food security. A few commonly used measures are:

(a) Calorie intake. This approach measures severity of undernourishment based on calorie intake. This is the dietary energy consumption per person which is the amount of food, in kilocalorie per day, for each individual in the population. Individuals are considered undernourished if the calorie intake is less than 1,800 kilocalories per day per person (ESCAP, 2014). This figure can vary between 1,630 and 2,000 kilocalories depending on countries. In 2010/11, Nepal's energy intake was 2,536 kilocalorie/person/day (WFP et al, 2013). (b) Global Hunger Index (GHI). GHI is adopted by International Food Policy Research Institute and is a tool designed to comprehensively measure and track hunger at the global, regional, and national levels (IFPRI, 2017). This index includes four equally weighted indicators, namely: (i) Undernourishment: the share of the population that is undernourished (i.e., whose caloric intake is insufficient); (ii) Child wasting: the share of children under the age of five who are wasted (i.e., low weight for height, reflecting acute undernutrition); (iii) Child stunting: the share of children under the age of five who are stunted (i.e., low height for age, reflecting chronic undernutrition); and (iv) Child mortality: the mortality rate of children under the age of five (i.e., a reflection of the fatal mix of inadequate nutrition and unhealthy environments).

GHI score ranges from 0 to 100 -point scale, where 0 is the best score (no hunger) and 100 the worst score. Categorically, 0-9.9 is low, 10-19.9 is moderate, 20-34.9 is severe, 35-49.9 is alarming and 50 plus is considered as extremely alarming hunger situation. Nepal's GHI in 2017 is severe with a score of 22, down from 42.5 (alarming) in 1992.

(c) Global Food Security Index (GFSI). GFSI combines measures of food affordability, availability, quality and safety. This index is developed by the Economist Intelligence Unit (EIU) (The Economist Intelligence Unit, nd). The index is estimated using 28 indicators for 113 countries. This scale value of this index ranges from $0-100$, where 0 is worst and 100 is best. In 2017, Nepal's overall GFSI score is 44.5 with a rank of 81 (out of 113). Affordability score is $\mathbf{3 7 . 7}$, availability score is 49.6 and the quality and safety score is 47.9 .

(d) Food Insecurity Multidimensional Index (FIMI). It is now widely recognized that food security is a multidimensional issue and cannot be adequately measured by a single indicator (Napoli, 2010/11). To measure this issue, a Food Insecurity Multidimensional Index (FIMI) synthetizes the four dimensions of food security availability, access, utilization and stability of food.

(e) Household Food Insecurity Access Scale (HFIAS). The Household Food Insecurity Access Scale (HFIAS) is developed by Food and Nutrition Technical Assistance (FANTA) of USAID. This measure assesses whether households experienced problems with food access during the past reference period (Coates et. al, 2006; 2007). The scale provides information on a household's "access" to food, one of the important dimensions of food insecurityavailability, access, utilization and stability. The instrument consists of nine occurrence questions and nine frequency questions. These items solicit information about food security problems faced by households as a result of limited resources to acquire food. This tool measures the level of household food insecurity during the past 30 days as reported by the household.

HFIAS defines food insecurity in terms of three domains of food insecurity (a) anxiety and uncertainty about household food supply, (b) insufficient quality that includes variety and preferences of food types, and (c) insufficient quantity of food intake. 
(i) Anxiety and uncertainty about household food supply. This domain "anxiety" is measured by asking "Did you worry that your household would not have enough food?" to measure whether a household experienced uncertainty and anxiety about acquiring food during specific period ${ }^{1}$.

(ii) Insufficient quality - less variety of preferred foods. This domain measures whether a household experienced having limited choices in the type of food that a household eats during specific period. This domain includes dietary choices related to variety-whether a household had to eat undesired monotonous diet or not. Following items are asked:

- Were you or any household member not able to eat the kinds of foods you preferred because of a lack of resources?

- Did you or any household member have to eat a limited variety of foods due to a lack of resources?

- Did you or any household member have to eat some foods that you really did not want to eat because of a lack of resources to obtain other types of food?

(iii) Insufficient quantity - smaller amount of food. This domain measures whether a household had to cut the amount of food during specific period due to a lack of resources. Followings items are asked to measure this domain.

- Did you or any household member have to eat a smaller meal than you felt you needed because there was not enough food?

- Did you or any household member have to eat fewer meals in a day because there was not enough food?

- Was there ever no food to eat of any kind in your household because of a lack of resources to get food?

- Did you or any household member go to sleep at night hungry because there was not enough food?

Did you or any household member go a whole day and night without eating anything because there was not enough food?

Each of these items is measured in a scale of $0-3$ $(0=$ never, $1=$ rarely, $2=$ sometimes and $3=$ often $)$. The type and number of occurrence indicators and time frame may be modified depending upon the context. For example, the Nepal Demographic Health Survey has reduced the number of occurrence items to 7 and the time frame has been increased to 12 months to adjust for the local context and seasonality (NDHS, 2011), one of the major limitations of this data.

A Household Food Insecurity Access Scale (HFIAS) is calculated using these nine items. HFIAS is the sum of the frequency of occurrence of aforementioned items during the past reference period (past month or past year). Because each of these items are measured in a scale of $0-3$, the responses may be assigned either: (a) a numerical value (0-27, $0-21$ if only 7 items) by summing up these items (higher numbers in the scale represent a greater level of food insecurity and vice versa) or (b) are categorized

1-Recall period may vary -in the past 30 days or "in the past 12 month" depending upon the context. as - food secure, mildly food insecure, moderately food insecure, and severely food insecure households (Coates et al., 2007; NDHS, 2011). This paper utilizes HFIAS as the indicator of household food insecurity, however, utilizes only seven items as measured in NDHS (2011).

\section{Regional Context and Food Security in Nepal}

Nepal comprises of three ecological regions: mountains, hills and the Tarai. These regions run east to west parallel from north to south. Significant variations exist among these three ecological regions in terms of climate, biogeography, resources, infrastructure and socioeconomic development.

The mountain region accounts for $35 \%$ of the total land area, ranges in altitude from 4,877 meters to 8,848 meters above sea level and covers a land area of 51,817 square kilometers. In 2011, approximately 7\% of the total population lived in this region (Government of Nepal, $2012 \mathrm{~b}$ ). This region has rugged terrain, poor agriculture and the minimal industrial production potential as compared to other regions. Basic facilities such as transportation, education, communication, drinking water, sanitation, electricity and almost all aspects of economy are less developed compared to the hill and Tarai regions (Asian Development Bank, 2002; Government of Nepal, 2012b).

The hill region ranges in altitude from 610 meters to 4,876 meters above sea level. This region is densely populated. About $43 \%$ of the total population lives in the hill region. This region occupies about $42 \%$ of the total land area and includes the Kathmandu Valleythe federal capital city of Nepal. Although the terrain is rugged and uneven, because of the high concentration of people and geopolitical reasons, this region has always received significant attention from the central government (Shrestha, 2001). As a result, this region has good access to basic facilities such as transportation, education, communication, drinking water, sanitation, electricity and health care facilities than that of the mountain region (Shrestha, 2001; Government of Nepal, 2012b).

The Tarai region in the southern plain has a subtropical to tropical climate and covers 23\% (34,019 square kilometers) of land. The Tarai region has the most fertile land in the country and is thus known as "the granary" (Gurung, 1998). While the Tarai holds only one-fourth of the total land area, about $50 \%$ of the population lives here (Government of Nepal, 2012b). Due to its relatively flat terrain, transportation and communication facilities, and other infrastructure, this region is relatively well developed compared to the other regions. This region receives significant attention from the central government (Government of Nepal, 2012b; ICF International and PDMDP, 2011).

Historically, there is a wide disparity in the socioeconomic wellbeing of the population in these three ecological regions (Bhandari et al., 2007; NESAC, 1998; Asian Development Bank, 2002; Bhandari et al., 2007; Government of Nepal, 2012; Nawal and Goli, 2013b; Goli et al., 2013). The Human Development Report 2014 (Government of Nepal, 2014) reported that in 2011, the 
human development index (HDI) for Nepal was 0.490 . The mountain region has the lowest HDI of 0.440 , which was followed by the Tarai region (0.468) and the hills (0.520). According to Agriculture Atlas (Government of Nepal, 2012), although the incidence of poverty has dramatically declined between 1995-96 and 2010-11, in 2010-11, 25 percent of population was poor compared to 31 percent in 2003-04 and 42 percent in 1995-96. The recent Nepal Living Standards Survey [NLSS] reported that poverty in Nepal is still deeply rooted and the mountain region is vulnerable to poverty (Government of Nepal, 2012b). The Human Poverty Index (HPI) is the lowest in the Hills at 29.20 and highest in the Mountains at 38.51. Moreover, both the Mountains and interestingly the Tarai regions have HPI values less than the national average. Based on this background, there is strong reason to believe that there is variation in household level poverty in the mountains, the hills and Tarai region.

According to 2011 population census, still 83 percent of population in Nepal lives in rural areas. Most of the development infrastructures and public services are concentrated in urban areas. There are clear rural-urban differences in socio-economic indicators in the country favoring urban areas. Rural locations are disadvantaged in almost every sector of economy including food security. For example, in 2011, the human development index (HDI) for rural areas was 0.464 as against 0.579 in urban areas (Government of Nepal, 2014). Similarly, this same document reports that rural poverty is nearly 1.8 times higher than urban poverty. Given these scenarios, there is strong reason to believe that the households in rural areas will have higher food insecurity status as compared to the households that reside in urban areas.

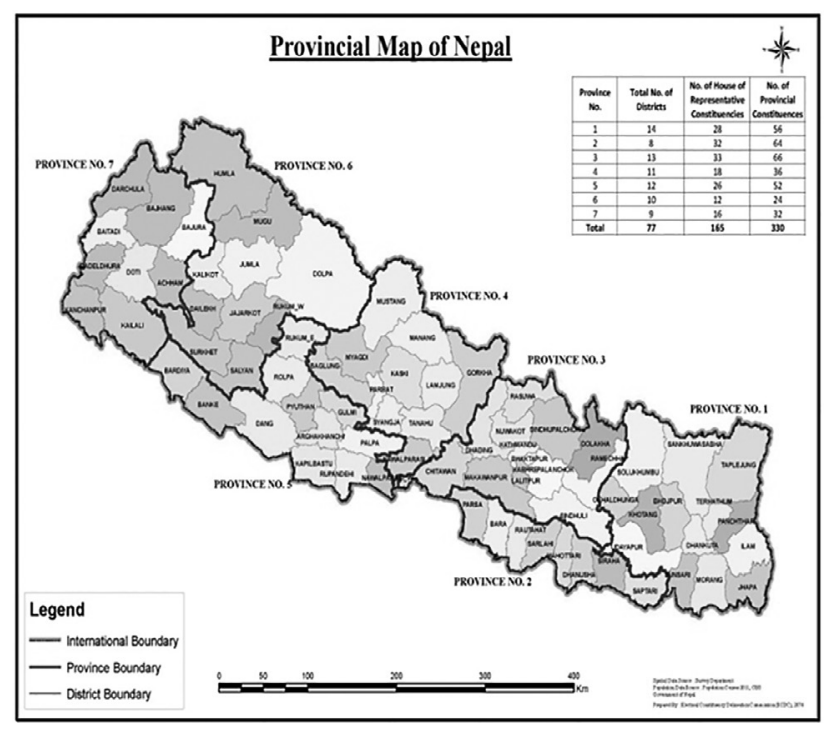

Nepal under federalism consists of seven federal states/ provinces (Fig. 1). Provinces 1 through 7 are geographically distributed from east to west. Of the total 75 districts $^{2}$ (77 districts in the new constitution) in the country, 14 districts are in province 1,8 districts in province 2,14 districts in province 3, 11 districts in Gandaki province) (province 4), 13 districts in province 5, 10 districts in Karnali province (province 6) and 9 districts in Far-western province (province 7). All the districts of province 2 are in the Tarai region and all the districts of Karnali province (province 6) are in the hills and mountains. Other provinces include at least some districts from the Tarai region.

Karnali and Far-western province (province 6 and 7) include districts where most socio-economic development indicators are among the lowest. Households in most of these districts in these two provinces have least access to nearby facilities such as early child development centers; schools; health facilities, transportation; shops and markets; banks; agricultural centers; drinking water; internet access; police stations; post offices and community centers (Government of Nepal, 2014). In 2011, the human development index (HDI) for the mid-western region was 0.447 and far-western region was 0.435 as against $0.499,0.510$ and 0.490 respectively for western, central and eastern development regions (Government of Nepal. 2014). Moreover, Karnali province includes several districts such as Dolpa, Jumla, Kalikot, Bajura and Humla with the lowest life expectancy. Far-western province includes districts from the far-western mountains (with the lowest HDI of 0.386) and hills (HDI=0.409). On the other hand, Gandaki province (province 4) includes districts with relatively higher HDI index. The Human Poverty Index (HPI) that captures exclusion based on income and capability deprivation also greatly varies by province. Districts in mid-western and far-western region that belong to provinces 6 and 7 are among the high HPI districts in the country. Based on these evidences, there is reason to believe that there is variation in food security of households by province.

\section{Methods}

\section{Data}

I used the nationally representative Nepal Demographic Health Survey (NDHS) data collected in 2010-11 to investigate household level food security by geographic regions. The purpose of NDHS was to collect information and provide estimates of key population and health indicators for the country as a whole using a representative sample. The research design itself is multi-level in nature, and therefore, used multi-stage sampling procedure to identify samples. The detailed procedure for sampling and data collection is provided in the NDHS 2011 report (Ministry of Health and Population (MOHP) [Nepal], New ERA, and ICF International Inc., 2012). To be brief, in Nepal, there are 75 administrative districts (recent federal structure under new constitution has 77 districts). Before the implementation of the new constitution promulgated in 2072, the districts were divided into administrative units called Village Development Committees (VDCs)

\footnotetext{
2- Both Rukum and Nawalparasi districts are divided into two districts under Nepal's new constitution of 2015. Because the data is aggregated at the district level, Rukum (both east and west) is included in Province 6 and Nawalparasi (both east and west) is included in Province 5.
} 
and municipalities. These VDCs and municipalities were further divided into smallest administrative units called wards. For the purpose of this survey, in the first stage, in each district, an enumeration area (EA) or a cluster was defined and selected which is a ward in VDCs and a subward (wards divided into sub-wards) in municipalities. Altogether, a total of 289 EAs (194 rural and 95 urban) were selected. In the second stage, upon complete household listing of all EAs, 35 households from each rural cluster and 40 households from each urban cluster were randomly selected.

Data was collected from households (household level information) and individual information was collected from women and men. Three questionnaires were administered - the Household Questionnaire, the Women's Questionnaire and the Men's Questionnaire.

The data utilized in this study comes from the household questionnaire that collected household level information including the food security status of a household from 10,826 households. Of particular interest to this study, this data contains information on householdlevel food security status reported by a household member by geographic regions - three ecological regions (mountain, hill and Tarai), rural-urban and by district. The survey measures household food security using the seven indicators of the Household Food Insecurity Access Scale (HFIAS). The survey used multi-stage cluster sampling to select a nationally representative sample of households $(10,826$ households) (for details refer to ICF International and PDMDP, 2011).

\section{Measures}

\section{Outcome measures - measures of food insecurity}

As indicated earlier, I used the following four outcomes:

(a) Anxiety and uncertainty about household food supply. This domain "anxiety" is measured by asking "Did you worry that your household would not have enough food?" to measure whether a household experienced uncertainty and anxiety about acquiring food in the past 12 months. The three responses 'rarely, sometimes and often' are coded as 1 (food insecure) and 'never' is coded as 0 (food secure).

(b) Insufficient quality - less variety of preferred foods. This domain measures whether a household experienced having limited choices in the type of food that members ate during the past 12 months. This domain includes dietary choices related to variety - whether household members had to eat undesired monotonous diet or not due to a lack of resources. Three items, (a) Were you or any household member not able to eat the kinds of foods you preferred because of a lack of resources? (b) Did you or any household member have to eat a limited variety of foods due to a lack of resources?, and (c) Did you or any household member have to eat some foods that you really did not want to eat because of a lack of resources to obtain other types of food? were used to measure this domain. The responses 'rarely, sometimes and often' are coded as 1 (food insecure) and 'never' is coded as 0 (food secure). (c) Insufficient quantity - smaller amount of food. This domain measures whether a household had to cut the amount of food during specific period due to a lack of resources. Three items, namely, (a) How often did you or any household member have to eat a smaller meal than you felt you needed because there was not enough food?, (b) How often did you or any household member eat fewer meals in a day because of lack of resources to get food; and (c) How often was there with no food to eat of any kind in your household because of lack of resources to get food; and (iii) how often did you or any household member go to sleep at night hungry because there was not enough food were used. The responses 'rarely, sometimes and often' are coded as 1 (food insecure) and never is coded as 0 (food secure).

(d) The Household Food Insecurity Access Scale (HFIAS). I also calculated the food insecurity index which is the sum of the frequency of occurrence during the past 12 months. Each of these item is measured in a scale of $0-3(0=$ never, $1=$ rarely, $2=$ sometimes and $3=$ often $)$. The summated index or scale ranged from $0-21$ that was resulted by summing up the seven items. A higher number in the scale represents a greater level of food insecurity.

\section{Explanatory measures}

(1) Households location by ecological regions. Location of households by ecological regions is grouped into three categories - mountain, hill and the Tarai. As the Tarai region is considered as the 'bread basket' or the 'granary' of the country, this region is used as the reference category.

(2) Rural-urban location of households. Rural-urban location of households is another geographic region used in the analysis. The disadvantaged rural location of a household is considered as the reference category.

(3) Location of households by province. As indicated earlier, there are seven provinces in Nepal. Province 6 lies in the western-northern region of Nepal which has among the lowest socio-economic development indicators. Moreover, this province has the least amount of agricultural food production resources. Thus, this province is considered as the reference category.

\section{Analytic Strategy}

First, descriptive statistics of the measures used in this study are calculated (Table 1). To examine whether these invariable distributions hold true or not, these results are adjusted. Thus, next, as the data was multilevel in nature, multivariate models using multilevel modeling (hierarchical linear modeling) techniques were estimated. The first outcome measure, household food security scale is a continuous measure (model 1 in Table 2). Thus, a multilevel OLS regression model was estimated using PROC MIXED SAS procedure. For dichotomous outcomes that measured household level food insecurity as food insecure $(=1)$ vs. food secure $(=0)$ with hierarchical structure of the data, multilevel logistic regression models were estimated using the SAS GLIMMIX procedure 
(models 2-4 in Table 2). These SAS procedures take into account of clustering of households by geographic clusters (Garson, 2013).

\section{Descriptive Results}

\section{Food Security by Ecological Regions}

Household level food insecurity for each ecological region by domain is provided in Table 1. Over all, the household food insecurity score is lower in Terai region (3.48) than in the hills (4.00) and in the mountain (4.03) (Table 1). By domains, the distribution shows that 51 percent of the households in the hill, 53 percent in the mountain and 60 percent in the Terai region reported that they were anxious and uncertain about household food supply in the past 12 months.

Another domain of food security is the access to the type of food the household members eat. This domain measures whether household members had to eat undesired monotonous diet (little diversity in food choices) in the past year. The access to the variety of food is measured by asking three items: in the past 12 months, (i) how often were you or any household member not able to eat the kinds of foods you preferred because of a lack of resources; (ii) how often did you or any household member have to eat a limited variety of foods due to a lack of resource; and (iii) how often did you or any household member have to eat a smaller meal than you felt you needed because there was not enough food.
By ecological region, 55 percent of the households in the mountain, 50 percent household in the hills and 43 percent households in the Tarai reported that they had to limit variety of (insufficient quality) of food in the past 12 months.

The next domain of food insecurity is the limited quantity of food. This is the measure whether household members had to eat lesser amount of food in the past 12 months. This domain includes variety and preferences of the type of food consumed by households. This domain is measured by asking three items: in the past 12 months, (i) how often did you or any household member eat fewer meals in a day because of lack of resources to get food; (ii) how often was there with no food to eat of any kind in your household because of lack of resources to get food; and (iii) how often did you or any household member go to sleep at night hungry because there was not enough food. Only 18 percent of households each in the mountains and hills and 21 percent households in the Terai reported that they had insufficient amount of food intake in the past 12 months. Interestingly, slightly more households reported eating smaller quantity of food in the bread basket region compared to the hills and the mountains.

\section{Rural Urban Differences in Food Security}

Evidence shows that there is a difference in household's food security status in rural and urban areas. On average, the food insecurity score is lower in urban areas (2.42) than in rural areas (4.35) (Table 1). Households in rural

Table 1. Yearly household food security (percent) by regions of Nepal, NDHS, 2011.

\begin{tabular}{lccccccc}
\hline \multicolumn{1}{c}{ Province } & $\begin{array}{c}\text { Food Insecurity } \\
\text { Access Scale\$ } \\
\text { (mean/std. deviation) }\end{array}$ & $\begin{array}{c}\text { Worry about } \\
\text { food supply }\end{array}$ & $\begin{array}{c}\text { Insufficient quality } \\
\text { - variety of foods }\end{array}$ & $\begin{array}{c}\text { Insufficient food } \\
\text { intake (amount) }\end{array}$ \\
& Secure\# & Insecure & Secure\# & Insecure & Secure\# & Insecure \\
\hline Ecological regions & $4.03(4.71)$ & 47 & 53 & 45 & 55 & 82 & 18 \\
Mountain & $4.00(4.84)$ & 51 & 49 & 50 & 50 & 82 & 18 \\
Hill & $3.48(4.86)$ & 60 & 40 & 57 & 43 & 79 & 21 \\
Tarai & & & & & & & \\
Rural-urban & $2.42(4.13)$ & 69 & 31 & 67 & 33 & 87 & 13 \\
Urban & $4.35(4.98)$ & 48 & 52 & 46 & 54 & 78 & 22 \\
Rural & & & & & & & \\
By Province & $2.80(4.10)$ & 61 & 39 & 61 & 39 & 86 & 14 \\
1 & $4.40(6.06)$ & 56 & 44 & 58 & 42 & 71 & 29 \\
2 & $2.96(4.03)$ & 60 & 40 & 57 & 43 & 88 & 12 \\
3 & $2.71(3.99)$ & 63 & 37 & 62 & 38 & 90 & 10 \\
4 (Gandaki) & $3.89(4.68)$ & 53 & 47 & 50 & 50 & 78 & 22 \\
5 & $7.94(5.89)$ & 26 & 74 & 23 & 77 & 57 & 43 \\
6 (Karnali) & $4.74(5.01)$ & 40 & 60 & 40 & 60 & 77 & 23 \\
7 (Far-west) & & & & & & & \\
\end{tabular}

\# Responses such as rarely, sometimes and often are grouped as food secure and never is coded as food secure.

$\$$ Scale ranges from 0-21. High value means high food insecurity. 
areas expressed that they were food insecure as compared to their urban counterparts in terms of specific domains of food security as well. While 52 percent of the households in rural area were worried that the household would not have enough food in the past 12 months as compared to only 31 percent households in urban areas. Similar proportion of rural households reported so for insufficient quality. There was also a rural-urban gap in the amount of food intake (13 percent in urban areas vs. 22 percent in urban areas). However, the proportion of households was much smaller as compared to other two domains.

\section{Food Security by Federal States/Provinces}

Food security situation in Nepal greatly varies by province (Table 1). The food insecurity access score is among the highest in Karnali province (province 6) (7.94) that belongs to the far western-northern part of Nepal, followed by Farwest province (province 7) (4.74) and province 2 (4.40). On the other hand, the most food secure households were located in Gandaki province (province 4) (2.71) which is followed by province 1 (2.80) and province 3 with a score of 2.96.

In terms of anxiety and uncertainty about household food supply, households in province 6 were the most insecure. Nearly three quarter (74\%) of households in this province reported that they were anxious and uncertain about food supply in the past 12 months. This province is followed by provinces 7 (Far-west), 5, 2, and 3. Households in Gandaki (province 4) (37\%) and province 1 (39\%) were relatively in better situation.

Food insecurity as measured in terms of insufficient quality also varied by province. Households in provinces 6 and 7 were among the most food insecure. Nearly equal proportion of households in province 6 and 7 (78\% and $77 \%$, respectively) reported insufficiency in terms of quality of food in the past 12 months. The least proportion of households were in provinces $4(38 \%)$ and $1(39 \%)$. Similarly, households in province 6 reported the most food insecure in terms of food intake among seven provinces. Interestingly, the bread basket province 2 ranked the in terms of reporting insufficiency in the amount of food intake after province 6 .

\section{Multivariate Results}

Earlier I described the unadjusted descriptive results by

Table 2. Multilevel models (models $1-3=$ odds ratios and model $4=$ unstandardized regression coefficients) estimating regional differentials in food insecurity, 2011 ( $\mathrm{N}=10,826$ households).

\begin{tabular}{|c|c|c|c|c|}
\hline Measures & $\begin{array}{l}\text { Overall food insecurity } \\
\text { (score) } \\
\text { (Model 1) }\end{array}$ & $\begin{array}{c}\text { Anxiety and } \\
\text { uncertainty } \\
\text { about food supply } \\
\text { (Model 2) }\end{array}$ & $\begin{array}{l}\text { Insufficient quality } \\
\text { (Model 3) }\end{array}$ & $\begin{array}{l}\text { Insufficient food } \\
\text { intake (Model 4) }\end{array}$ \\
\hline \multicolumn{5}{|l|}{ Explanatory variables } \\
\hline \multicolumn{5}{|l|}{ Ecological regions } \\
\hline \multicolumn{5}{|l|}{ Tarai (Reference) } \\
\hline Mountain & -0.02 & $1.56^{* *}$ & 1.29 & $0.68+$ \\
\hline Hill & 0.34 & $1.47 * *$ & 1.22 & 0.79 \\
\hline \multicolumn{5}{|l|}{ Rural-urban } \\
\hline Urban (Reference) & - & - & - & - \\
\hline Rural & $1.72 * * *$ & $2.45^{* * *}$ & $1.58 * * *$ & $1.85^{* * *}$ \\
\hline \multicolumn{5}{|l|}{ Federal provinces } \\
\hline $\begin{array}{l}\text { Province } 6 \text { (Karnai) } \\
\text { (Reference) }\end{array}$ & - & - & - & - \\
\hline Province 1 & $-4.72 * * *$ & $0.22 * * *$ & $0.16^{* * *}$ & $0.19 * * *$ \\
\hline Province 2 & $-3.01 * * *$ & $0.37^{* * *}$ & $0.22 * * *$ & $0.41 * * *$ \\
\hline Province 3 & $-4.49 * * *$ & $0.23 * * *$ & $0.20 * * *$ & $0.18^{* * *}$ \\
\hline Province 4 (Gandaki) & $-4.87 * * *$ & $0.21 * * *$ & $0.16^{* * *}$ & $0.14 * * *$ \\
\hline Province 5 & $-3.53 * * *$ & $0.40^{* * *}$ & $0.32 * * *$ & $0.29 * * *$ \\
\hline Province 7 (Far-west) & $-2.74 * * *$ & $0.64+$ & $0.49 * *$ & $0.34 * * *$ \\
\hline Intercept & 6.14 & 1.08 & $1.59+$ & $0.52 *$ \\
\hline Deviance (-2 R log LL) & $\begin{array}{c}62078.9 \\
(\mathrm{Null}=62211.90) \\
\end{array}$ & $\begin{array}{c}13267.17 \\
(\text { Null=13417.81) } \\
\end{array}$ & $\begin{array}{c}13198.28 \\
\text { (Null=13344.86) }\end{array}$ & $\begin{array}{c}9311.17 \\
\text { (Null=9395.36) } \\
\end{array}$ \\
\hline
\end{tabular}

$+\mathrm{p}<.10, * \mathrm{p}<.05, * * \mathrm{p}<.01, * * * \mathrm{p}<.001$.

Note: Outcomes for model 1 is a HFIAS score - a continuous measure that ranges from 0-21.models. For models 2-4, outcomes are binary categories: food insecure $=1 \mathrm{vs}$. food secure $=0$. 
regions. These unadjusted raw distributions suggest that there is regional inequality (by ecological regions, ruralurban and province) in household-level food insecurity. Do these results still hold true after adjusting for ruralurban, ecological and provincial level variations in food insecurity? This analysis is important to understand whether the existing invariable variations still hold true even after adjusting for rural-urban, ecological and provincial level variations. Below I discuss the adjusted results from multilevel multivariate unstandarized regression coefficients (Table 2, model 1) and odds ratios (models 2 to 4 ).

\section{Overall Food Insecurity (Score) by Regions}

The unstandarized results (from Table 1) show that the overall food insecurity score reported by households is slightly higher in the mountains (4.03) and hills (4.00) as compared to the Terai (3.48). However, after adjusting for rural-urban and provincial level variations, the difference in food insecurity score among three ecological regions in fact is not statistically significant (model 1 , Table 2).

Results from Table 2 show that there is a difference in food security status of households by rural-urban location. More households in rural areas expressed that they were food insecure as compared to their urban counterparts net of other regions. Adjusting for ecological and provincial level variation, households in rural areas are 0.72 times higher in the food insecurity score (regression coefficient of $1.72, p<.001$, model 1) to report that they were worried about household food supply in the past 12 months than those living in urban areas.

If we examine the food insecurity score by federal provinces, the adjusted results show that the households living in all other six provinces had significantly lower (negative regression coefficients) as compared to those living in Karnali province (province 6). The difference was much higher for provinces Gandaki (province 4), 3 and 1. For example, the households in Gandaki province (province 4) have 4.87 points lower food insecurity score (regression coefficient $=-4.87, \mathrm{p}<.001$, model 1 ) as compared to those living in Karnali province (province 6). These results clearly suggest that overall food insecurity is more of rural-urban and/or provincial phenomena than ecological regions.

This study further examined if there is any variation in food insecurity by food security domains. Results from multivariate analysis (models 2-4) suggest that there are differences by specific domain of food security by regions.

Anxiety and Uncertainty about Food Supply by Regions: Although I did not find a significant difference in overall food insecurity score by ecological regions, the response of households about anxiety and uncertainty about food supply in the past 12 months significantly differed. Adjusted results show that the households in the mountain and hill regions were $56 \%$ (odds ratio $=1.56, \mathrm{p}<.001$, model 2 ) and $47 \%$ (odds ratio $=1.47, \mathrm{p}<.001$, model 2 ) more likely to report anxiety and uncertainty about food supply in the past 12 months as compared to those living in the 'bread basket' or 'granary' of the overall Tarai region.

Provincial level difference in food security status of households was also clear. The households living in all other provinces reported lower odds of anxiety and uncertainty about food supply as compared to those living in Karnali province (province 6). For example, the households in Gandaki province (province 4) have 79 points lower odds (odds ratio $=0.21, \mathrm{p}<.001$, model 2 ) in food insecurity as compared to those living in Karnali province (province 6). The magnitude of the difference differed by provinces. These results imply that households in the mountain and the hills, rural and urban areas and by province were concerned about overall food supply.

Insufficient Quality of Food by Regions: By ecological region, unadjusted results showed a clear variation in food insecurity status of households in terms of insufficient quality of food. Over 55 percent of the households in the mountain, 50 percent in the hills and 43 percent in the Tarai reported that they had to eat limited variety (insufficient quality) of food in the past 12 months. However, when the analysis is adjusted for rural-urban and provincial level differences, the result is not statistically significant. Again, there is a clear rural-urban difference. Adjusted results show that the households in rural areas were $58 \%$ (odds ratio $=1.58, \mathrm{p}<.001$, model 3 ) more likely to report that they had to limit variety of food in the past 12 months than those that are living in the urban areas, net of ecological regions and provincial variation.

By province, the households living in all other provinces reported lower odds of anxiety and uncertainty about food supply as compared to those living in Karnali province (province 6). For example, the households in Gandaki province (province 4) have 79 points lower odds (odds ratio $=0.21, \mathrm{p}<.001$, model 2) as compared to those living in Karnali province (province 6). Again rural households and the households in Karnali province (province 6) required more attention to address food security problem related to quality of food in the country.

Insufficient Quantity of Food Intake by Regions: Next domain of food insecurity is the limited quantity of food household members had to eat lesser amount in the past 12 months. Although the unadjusted results show variations in food security status of households in terms of quantity of food by ecological region, the adjusted results show that the differences are simply because of chance. While the households in the mountain and the hills unexpectedly reported lower odds of food insecurity in terms of food intake as compared to those in the Tarai region, the results were not statistically significant.

Rural-urban and provincial level differences in food security status of households in terms of quantity of food intake were statistically significant, however. Adjusted results show that the households in rural areas were 85 $\%$ (odds ratio $=1.85, \mathrm{p}<.001$, model 4$)$ more likely to report that they had to eat lesser amount of food in the past 12 months than those that are living in urban areas. Similarly, the households living in all other provinces reported statistically significantly lower odds of having to eat smaller amount of food as compared to those living in 
Karnali province (province 6).

\section{Conclusion and Implications}

Food security is a complex and multidimensional concept. Measuring the concept with a single indicator is difficult due to its complexity and context specificity. In this paper, I examine the regional inequality of household food security using the Household Food Insecurity Access Scale (HFIAS) indicators in Nepal using data from 10,826 households that come from the nationally representative 2011 Nepal Demographic Health Survey.

Nepal has a varied geography - from the 'bread basket,' the flat Tarai region to the hills and the high Mountains. These three major ecological regions have varied climate, soils, cropping patterns and productive potentials. Moreover, from a development perspective, these regions have differential development infrastructures and the access to public services.

Empirical evidences show a clear regional pattern in overall food security status of households in Nepal. Food security is a problem of rural households as compared to those of urban households. Despite the fact that many households in rural areas are engaged in agriculture, food security in these households is more pronounced than those in urban areas. This may be specifically due to the distribution of imported food in urban areas as compared to those in rural areas. In addition, food security status of households also varied by province. Households living in Karnali province (province 6) and Far-west (province 7) seem to be more food insecure as compared to those in other provinces. Moreover, food security status of households also varied by domains of food security. While anxiety about food supply was an issue for all households, other two domains were important for households that are located in rural areas and those that live in Karnali (province 6) and Far-west (province 7) provinces.

These findings provide a macro level scenario of food security situation of Nepal. These findings broadly inform the newly formed provincial governments the food security situation in their provinces. In conclusion, geographical difference is important and each province should adopt a differential policy to address their food security challenge at the macro level.

While this paper addresses important gap in existing research using the nationally representative data with multi-level characteristics, this paper is not free from limitations. One of the major limitations is its crosssectional nature. These results are rather associational and therefore, these conclusions should be considered rather cautiously. A detailed longitudinal data with panel structure is required to offer more conclusive guidance. Moreover, the measures of food security items are mere perceptions of the respondents that may not reflect the actual situation of individuals. More importantly, these are crude measures and more refined indicators of food security may be used to arrive at logical conclusions. These items were measured for a time frame of 12 months posing a threat to recall accuracy. A further analysis by using more specific household level factors such as the access to various capital assets by households is needed to come up with more concrete policies at the micro-level.

\section{References}

Asian Development Bank (2002). "Poverty reduction in Nepal: Issues, findings, and approaches. http://www. adb.org/Documents/Reports/Poverty_Reduction NEP/ poverty_analysis.pdf (retrieved on September 20, 2005).

Bebbington, A. (1999). Capitals and capabilities: a framework for analyzing peasant viability, rural livelihoods and poverty. World Development 27(12), pp. 2021-2044.

Bhandari, P. B. (2013). Rural livelihood change? Household capital, community resources and livelihood transition. Rural Studies 32:126-136. PMCID: PMC3772533.

Bhandari, P., Shrestha, S. S., and Ghimire, D. J. (2007). Socio-cultural and geographical disparities in child immunization in Nepal. Asia-Pacific Population Journal 22(2), pp. 43-64.

Carney, D. (2002). Sustainable livelihoods approaches: progress and possibilities for changes. Department for International Development, London, UK.

Central Bureau of Statistics (2011). Nepal Living Standards Survey 2010/11: Statistical Report Volume Two. Central Bureau of Statistics. National Planning Commission Secretariat, Government of Nepal. Kathmandu.

Central Bureau of Statistics (2012). Population census 2011 - Preliminary Report. Government of Nepal. Kathmandu.

Coates, J., Frongillo, E. A., Rogers, B. L., Webb, P., Wilde, P. E., Houser, R. (2006). Commonalities in the experience of household food insecurity across cultures: What are measures missing? Journal of Nutrition 136(5): 1438S-1448S.

Coates, J., Bilinsky, A. S. P. (2007). Household Food Insecurity Access Scale (HFIAS) for Measurement of Food Access: Indicator Guide. Version 3. FANTA Food and Technical Assistance, USAID, Washington, DC. https://www.fantaproject.org/sites/default/files/ resources/HFIAS_ENG_v3_Aug07.pdf

DFID (1999). Sustainable livelihoods guidance sheets. Department for International Development, London, UK.

ESCAP (2014). Food security. statistical year book of Asia and the Pacific 2014. Economic and Social Commission for Asia and the Pacific. http://dx.doi. org/10.18356/395cec2b-en. http://www.unescap.org/ sites/default/files/17-Food-security-SYB2014.pdf

FAO (2006). Food security. policy brief. Issue 2, June 2006. http://www.fao.org/forestry/13128-0e6f36f27e0 091055bec28ebe830f46b3.pdf

FAO (1983). World food security: a reappraisal of the concepts and approaches. Director Generals Report, Rome.

FAO (2014). The state of food insecurity in the world 2014. Rome. http://www.fao.org/3/a-i4030e.pdf. 
FAO, WFP, \& IFAD (2013). The state of food insecurity in the world 2013: The Multiple Dimensions of Food Security. FAO, Rome.

Garson, G. D. (2013). Fundamentals of hierarchical linear and multilevel modeling. Hierarchical linear modeling: Guide and applications by Garson. Los Angeles, London, New Delhi, Singapore, Washington DC: Sage Publications Inc, pp. 3-26.

Goli, S., Bhandari, P., Atla, U. M. R., \& Chattopadhayay, A. (2017). Childhood Mortality Differentials by Ecological Region in Nepal: Childhood Mortality Differentials in Nepal. Population, Space and Place, 23(2), e1977. https://doi.org/10.1002/psp.1977

Government of Nepal 2071 (2014). National population policy 2071. Government of Nepal. Ministry of Health and Population, Kathmandu, Nepal.

Government of Nepal (2013). Nepal millenium development goals. Progress Report 2013. Government of Nepal. National Planning Commission Secretariat, Kathmandu, Nepal.

Government of Nepal (2015). Sustainable development goals 2016-2030. National (Preliminary) Report. National Planning Commission. Nepal. http://www. np.undp.org/content/dam/nepal/docs/reports/SDG\%20 final $\% 20$ report-nepal.pdf

Government of Nepal (2012). Agriculture atlas of Nepal. National Planning Commission Secretariat. Nepal.

Government of Nepal (2012b). Central Bureau of Statistics, National Planning Commission Secretariat. Available at http:// www.Central Bureau of Statistics. gov.np [Accessed 5 May 2011].

Gurung, H. (1998). Nepal social demography and expressions. Kathmandu: New Era.

ICF International and PDMDP (2011). Nepal Demographic and Health Survey: New ERA and Macro International Inc: Calverton, Maryland, USA and Kathmandu, Nepal.

IFPRI (2017). Global hunger index: the inequalities of hunger. International Food Policy Research Institute. Washington, DC. http://www.globalhungerindex.org/ pdf/en/2017.pdf.

Joshi, K. D., Conroy, C. and Witcombe, J. R. (2012). Agriculture, seed, and innovation in Nepal: Industry and policy issues for the future. International Food Policy Research Institute (IFPRI). Project Paper, December 2012. Washington, D.C.

Krantz, L. (2001). The sustainable livelihood approach to poverty reduction: an introduction. Sida, Swedish International Development Cooperation Agency, Division for Policy and Socio-Economic Analysis. Sweden.

Maxwell, D.G. (1996). Measuring food insecurity: The frequency and severity of coping strategies. Food Policy, 21(3): 291-303.

Napoli, M. (2010/11). Towards a food insecurity multidimensional index (FIMI). Master in Human Development and Food Security (2010/2011). nitroPDFprofessional.

Nawal D, Goli S. (2013). Inequality in utilization of maternal health care services in Nepal. Ethnicity and
Inequalities in Health and Social Care 6 (1), 3-15.

NDHS (2012). Ministry of Health and Population (MOHP) [Nepal], New ERA, and ICF International Inc. (2012). Nepal Demographic and Health Survey 2011. Kathmandu, Nepal: Ministry of Health and Population, New ERA, and ICF International, Calverton, Maryland. NESAC (1998). Nepal human development report 1998. Nepal South Asia Centre, Kathmandu, Nepal.

Scoones, I. (1999). Sustainable rural livelihoods: A framework for analysis. IDS Working Paper 72. Institute of Development Studies, Brighton, UK.

Shrestha, A. (2001). Bleeding Mountains of Nepal: a story of corruption greed and misuse of Power, Bloomington: Universe, incorporated.

Smith, M., Pointing, J. and Maxwell, S. (1993). Households food security, concepts and definitions; an annotated bibliography.

The Economist Intelligence Unit (nd). User guide for the Global Food Security Index: Understanding the index and leveraging it for your work. New York. www.eiu. com. Available at: http://foodsecurityindex.eiu.com/

UNDP (2011). Human Development Report 2011 Sustainability and Equity: A Better Future for All. UNDP, Washington, D.C.

United Nations (2017). The sustainable development goals report 2017. United Nations, New York.

USDA. nd. Definition of Food Security. https://www. ers.usda.gov/topics/food-nutrition-assistance/foodsecurity-in-the-us/definitions-of-food-security.aspx

van Vark, Caspar (2013). Food security: an urban issue. The Guardian. https://www.theguardian.com/globaldevelopment-professionals network/2013/dec/17/ africa-peri-urban-food-security

WFP, WB, UNICEF, AusAID, and CBS (2013). Nepal thematic report on food security and nutrition 2013. Kathmandu, Nepal: National Planning Commission.

World Food Summit (1996). Declaration on world food security. World Food Summit, 13-17 November, 1996, Rome. http://www.fao.org/docrep/003/w3613e/ w3613e00.htm.

Bhandari, Prem $\mathrm{PhD}$, is a Social Demographer. He has earned PhD in Rural Sociology and Demography from the Pennsylvania State University, Pennsylvania. Bhandari is currently working at the Population Studies Center at the University of Michigan. His research focuses on the socioeconomic and cultural determinants of human fertility, migration and remittances, and population health in developing countries. Other areas include rural social change, population and environment relationships, and social research methods. He has published several papers in peer-reviewed journals. He is also an occasional reviewer of a dozen of international peer-reviewed journals. Dr. Prem Bhandari is a member of international advisory board of Dhaulagiri Journal of Sociology and Anthropology.

Email:prembh@umich.edu 